\title{
Magnetically activated microcapsules as controlled release carriers for a liquid PDMS cross-linker
}

Kostrzewska, Malgorzata; Yu, Liyun; Li, Yang; Li, Jiansheng; Wenzell, Berit; Kasama, Takeshi; Skov, Anne Ladegaard

Published in:

Materials Research Express

Link to article, DOI:

10.1088/2053-1591/aae913

Publication date:

2019

Document Version

Peer reviewed version

Link back to DTU Orbit

Citation (APA):

Kostrzewska, M., Yu, L., Li, Y., Li, J., Wenzell, B., Kasama, T., \& Skov, A. L. (2019). Magnetically activated microcapsules as controlled release carriers for a liquid PDMS cross-linker. Materials Research Express, 6(1), [015310]. https://doi.org/10.1088/2053-1591/aae913

\section{General rights}

Copyright and moral rights for the publications made accessible in the public portal are retained by the authors and/or other copyright owners and it is a condition of accessing publications that users recognise and abide by the legal requirements associated with these rights.

- Users may download and print one copy of any publication from the public portal for the purpose of private study or research.

- You may not further distribute the material or use it for any profit-making activity or commercial gain

- You may freely distribute the URL identifying the publication in the public portal 
ACCEPTED MANUSCRIPT

\section{Magnetically activated microcapsules as controlled release carriers for a liquid PDMS cross-linker}

To cite this article before publication: Malgorzata Kostrzewska et al 2018 Mater. Res. Express in press https://doi.org/10.1088/2053-1591/aae913

\section{Manuscript version: Accepted Manuscript}

Accepted Manuscript is "the version of the article accepted for publication including all changes made as a result of the peer review process, and which may also include the addition to the article by IOP Publishing of a header, an article ID, a cover sheet and/or an 'Accepted

Manuscript' watermark, but excluding any other editing, typesetting or other changes made by IOP Publishing and/or its licensors"

This Accepted Manuscript is @ 2018 IOP Publishing Ltd.

During the embargo period (the 12 month period from the publication of the Version of Record of this article), the Accepted Manuscript is fully protected by copyright and cannot be reused or reposted elsewhere.

As the Version of Record of this article is going to be / has been published on a subscription basis, this Accepted Manuscript is available for reuse under a CC BY-NC-ND 3.0 licence after the 12 month embargo period.

After the embargo period, everyone is permitted to use copy and redistribute this article for non-commercial purposes only, provided that they adhere to all the terms of the licence https://creativecommons.org/licences/by-nc-nd/3.0

Although reasonable endeavours have been taken to obtain all necessary permissions from third parties to include their copyrighted content within this article, their full citation and copyright line may not be present in this Accepted Manuscript version. Before using any content from this article, please refer to the Version of Record on IOPscience once published for full citation and copyright details, as permissions will likely be required. All third party content is fully copyright protected, unless specifically stated otherwise in the figure caption in the Version of Record.

View the article online for updates and enhancements. 


\title{
Magnetically activated microcapsules as controlled release carriers for a liquid PDMS cross-linker
}

\section{Malgorzata Kostrzewska ${ }^{1}$, Liyun $\mathrm{Yu}^{1}$, Yang $\mathbf{L i}^{2}$, Jiansheng $\mathrm{Li}^{2}$, Berit Wenzell ${ }^{3}$, Takeshi}

\section{Kasama $^{3}$, Anne Ladegaard Skov ${ }^{1 *}$}

${ }^{1}$ Danish Polymer Centre, Department of Chemical and Biochemical Engineering, Technical University of Denmark, Søltofts Plads Building 227, 2800 Kgs. Lyngby, Denmark

2 Jiangsu Key Laboratory of Chemical Pollution Control and Resources Reuse, School of Environmental and Biological Engineering, Nanjing University of Science and Technology, 210094 Nanjing, P. R. China

${ }^{3}$ Center for Electron Nanoscopy, Technical University/of Denmark, Fysikvej 307, 2800 Kgs. Lyngby, Denmark

*Corresponding author: Tel.: +45 45252825. Fax: +45 45882258. E-mail: al@kt.dtu.dk

\begin{abstract}
Injecting water into a porous oil reservoir enhances oil sweep efficiency and leads to increased oil production, but due to the occurrence of fractures in water-flooded reservoirs, excessive water production is observed. Hence, water shut-off treatments are continuously investigated, albeit currently applied plugging materials still suffer from some disadvantages such as lack of selectivity and poor mechanical strength. In this work, we introduce a new plugging material consisting of vinyl-functional PDMS microspheres and magnetically activated microcapsules. This work focuses on the preparation and characterisation of microcapsules containing magnetite nanoparticles (MNPs), and liquid cross-linker in their core. The microcapsules are prepared via a phase separation technique, and it is established that the MNPs are located inside the microcapsules and that the shell remains nonporous, in which case the cross-linker is well
\end{abstract}


protected before activating the microcapsules. While exposed to an alternating magnetic field, the MNPs generate sufficient heat to soften the polymeric shell, thereby leading to the efficient release of the cross-linker; moreover, the PDMS microspheres create a strong network, due to a cross-linking reaction. It is expected that this new approach will improve significantly the plugging process of fractures in matured reservoirs, which in turn will lead to higher oil recovery rates.

Keywords: alternating magnetic field, magnetically activated microcapsules, PDMS microspheres, liquid cross-linker, magnetite

\section{Introduction}

Water-flooding treatment is applied when underground pressure in oil reservoirs drops notably and becomes insufficient to drive the oil to the surface. In this method, water is injected into porous reservoir rock to displace the oil and push it towards the production well [1,2], thereby increasing the pressure of the reservoir, which can be maintained for a long time. An illustration of the water flooding method is presented in Figure 1a. However, naturally occurring fractures decrease oil production because the injected water passes easily through fractures, leaving unswept oil in low-permeable, porous zones (Figure 1b). It is evident that in order to maintain oil production, the fractures need to be shut off to water (Figure 1c) [3]. Since successful fracture plugging in water-flooded oil reservoirs significantly increases oil recovery rates, relevant methods are being improved constantly. 

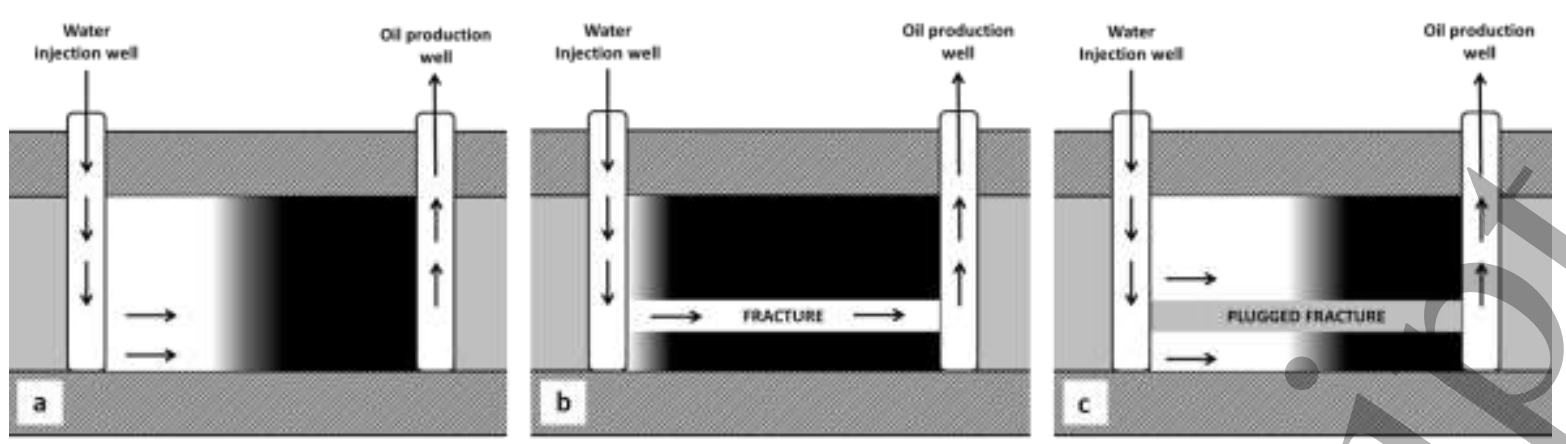

Figure 1. Illustration of a proposed water injection method in an oil reservoir. a) As fractures are not present in the reservoir, oil production is high due to a sufficient pressure difference. b) The presence of fractures leads to lower oil production, as water passes through the fracture easily. c) Plugging the fracture results in satisfactory oil production. White and black colours represent water and oil flows in the reservoir, respectively.

Nowadays, water shut-off is achieved mainly by injecting highly swellable polymeric hydrogels [4-8]. The most commonly used hydrogels can be divided into three main categories: inorganic gels (e.g. sodium silicate gel), polymer-based gels (e.g. acrylamide monomer-based and polyacrylamide gels) and preformed particle gels (PPG). The swollen gels show fairly good elastic properties and are capable of withstanding high pressures [9]. However, this technique suffers from some disadvantages. The hydrogels are injected into the reservoir in the form of low-viscosity mixtures, and although the swelling can be controlled to some extent, the hydrogels often start swelling well before placing the material inside the fracture, thus blocking the injection well. Moreover, polymer chains in the hydrogels are not covalently bonded, as they only swell and do not react chemically with each other, which causes poor set plug mechanical strength. Finally, due to the low viscosity of the mixtures, the hydrogel may seep into oil-rich pores and plug the whole reservoir, not only the fracture.

Poly(dimethylsiloxane) (PDMS) is the most commonly used of the polymeric organosilicon compounds, generally referred to as silicones, and it has been chosen for this 
work because of its unique properties, such as highly elasticity and excellent compressibility, hydrophobicity and outstanding resistance to oil at high temperatures [10]. The plugging material consists of vinyl-functional PDMS microspheres and magnetically activated microcapsules with a hydride cross-linker. After the cross-linker is released from the microcapsules, PDMS microspheres can be bonded covalently with each other through the hydrosilylation reaction [11].

This work deals with designing a novel plugging material that blocks fractures selectively and efficiently in a controllable way compared to the known plugging materials, i.e. hydrogels. PDMS is injected into the fracture in the form of pre-crosslinked microparticles, which do not swell in contact with water, and hence the danger of blocking the injection well, due to the premature swelling of the particles, is eliminated. The size of the PDMS microparticles can be designed to be smaller than the fracture width but larger than the pore diameter. In this way, the material will enter in the fracture only, without blocking the pores. As the PDMS particles are less deformable than hydrogels, they will not penetrate into pores even under high pressure. Moreover, the PDMS microparticles have reactive vinyl groups on the surface. These vinyl groups are capable of further reacting with the multi-functional crosslinker. After the reaction inside the fracture, each microparticle is covalently connected with other microparticles by a cross-linker, and a strong barrier is created. This makes the material even more durable and resistant to high pressure. In this way, the macroscopic PDMS elastomer cannot be washed away due to the injection of water and should cause long-term durability of the treatment.

An alternating magnetic field (AMF) is applied as an activating stimulus in this study, as it easily penetrates the materials and can be applied from a distance. When magnetic materials, for example magnetic nanoparticles, are subjected to AMF, they generate heat due to heat dissipation caused by the delay in relaxing the magnetic moment through either rotation within the particle (Néel mechanism) or rotation of the particle itself (Brownian mechanism) [12-14]. 
Magnetic material heating by AMF is used in many industrial processes, such as heat treatment in metallurgy and to melt refractory metals, which require very high temperatures [15]. The most commonly used magnetic nanoparticles are made from iron oxide, called magnetite [16], which contains both ferrous and ferric iron species [17,18]. Magnetic relaxation of magnetite is exploited in innovative biomedical magnetic particle applications such as magnetic particle imaging [19], magnetic fluid hyperthermia [20] and biosensing [21]. In this study, magnetite nanoparticles (MNPs) without and with non-reactive PDMS surface modifications were subjected to AMF, and their heating properties were examined. Subsequently, microcapsules with MNPs, which can be activated by applying the AMF, were prepared and characterised. The release of the cross-linker was expected after subjecting the microcapsules to AMF. The hypothesis is that at certain frequencies, MNPs generate enough heat to break microcapsules above the shell's glass transition temperature $\left(\mathrm{T}_{\mathrm{g}}\right)$.

\section{Experimental}

\subsection{Materials}

A hydride-functional cross-linker (HMS-301, $\left.\quad \mathrm{M}_{\mathrm{w}}=2000 \mathrm{~g} / \mathrm{mol}\right)$, vinyl-terminated poly(dimethylsiloxane) DMS-V22 $\left(\mathrm{M}_{\mathrm{w}}=9400 \mathrm{~g} / \mathrm{mol}\right)$ and DMS-V31 $\left(\mathrm{M}_{\mathrm{w}}=28000 \mathrm{~g} / \mathrm{mol}\right)$ were purchased from Gelest. Poly(yinyl alcohol) (PVA, $\mathrm{M}_{\mathrm{w}}=22000 \mathrm{~g} / \mathrm{mol}$ ), used as an emulsifier, was purchased from Fluka. Platinum cyclovintlmethyl siloxane complex Catalyst 511 was obtained from Hanse Chemie, whereas Inhibitor PT88 was purchased from Wacker Chemie. Poly(methyl methacrylate) (PMMA, $\mathrm{M}_{\mathrm{w}}=15000 \mathrm{~g} / \mathrm{mol}$ ), non-reactive silicone oil (methylterminated poly(dimethylsiloxane)) with viscosity $20 \mathrm{cSt}$, sodium dodecyl sulfate (SDS), dichloromethane $(\mathrm{DCM})$ and deuterated chloroform $\left(\mathrm{CDCl}_{3}\right)$ were acquired from SigmaAldrich. 
Magnetic nanoparticles $\mathrm{Fe}_{3} \mathrm{O}_{4}$ and $\mathrm{Fe}_{3} \mathrm{O}_{4}$-PDMS, with a diameter of approximately $50 \mathrm{~nm}$, were synthesised according the reported reference [22], and the experimental details are presented in electronic supplementary information (ESI).

\subsection{Preparation of magnetic microcapsules}

The preparation of microcapsules with a PMMA shell and a liquid cross-linker as a core was studied extensively in our previous work [23,24], that is microcapsules with a silicone oil core (methylhydrosiloxane-dimethylsiloxane, HMS-301) surrounded by a polymeric shell, PMMA was synthesized by the controlled phase separation of a polymer dissolved within the silicone oil droplets of an oil-in-water emulsion. The phase separation technique in this work, as illustrated in Figure 2, was adapted to prepare magnetic microcapsules as follows: an oil phase was prepared by adding the proper amount of the cross-linker (HMS-301) and the magnetite nanoparticles to an organic solvent, preceded by dissolving PMMA. This prepared oil phase was then placed in an ultrasonic bath for 2 hours, in order to obtain well dispersion of nanoparticles. Afterwards, approximately $150 \mathrm{~mL}$ of aqueous PVA emulsifier solution was charged to a $250 \mathrm{~mL}$ conical flask and the aqueous phase was mechanically stirred at $2000 \mathrm{rpm}$ for 2-5 min. The oil phase was added drop-wise over $60 \mathrm{~s}$ to form an oil-in-water emulsion. The agitation was maintained for further 2 hours at around $750 \mathrm{rpm}$. Microcapsule dispersion was filtered with a filtration pump. Finally, the product was washed with distilled water $(\sim 1.5$ L) and dried at room temperature. 


\subsection{Preparation of vinyl-functional PDMS microspheres}

Microspheres with vinyl groups on the surface were prepared using the emulsion method, as illustrated in Figure 3. First, a low-viscosity DMS-V22 premix, containing $50 \mathrm{ppm}$ of Pt catalyst and $0.1 \%$ of the PT88 inhibitor, was prepared, following which a proper amount of the cross-linker (HMS-301) was added to the premix, in order to obtain a stoichiometric imbalance equal to $r=0.8$. A stoichiometric imbalance in this case is the ratio between the number of hydride groups to the number of vinyl groups, which means that mixtures with a stoichiometric imbalance lower than 1 have an excess of vinyl groups. This prepared mixture was then mixed for 2 minutes at $2000 \mathrm{rpm}$, using a SpeedMixer (FlackTek Inc. DAC 150.1 FVZ-K). Next, the mixture was added to approximately $200 \mathrm{~mL}$ of aqueous surfactant solution (1wt.\% of PVA and $3 \mathrm{wt} . \%$ of SDS) and stirred mechanically at $2000 \mathrm{rpm}$ for 2 minutes, following which the speed was decreased to $750 \mathrm{rpm}$ and the reaction carried out at $80{ }^{\circ} \mathrm{C}$ for 3 hours. Finally, the microspheres were washed with deionised water and dried at room temperature. Further 
preparation details and characterisation of the PDMS microspheres are reported previously $[25]$.

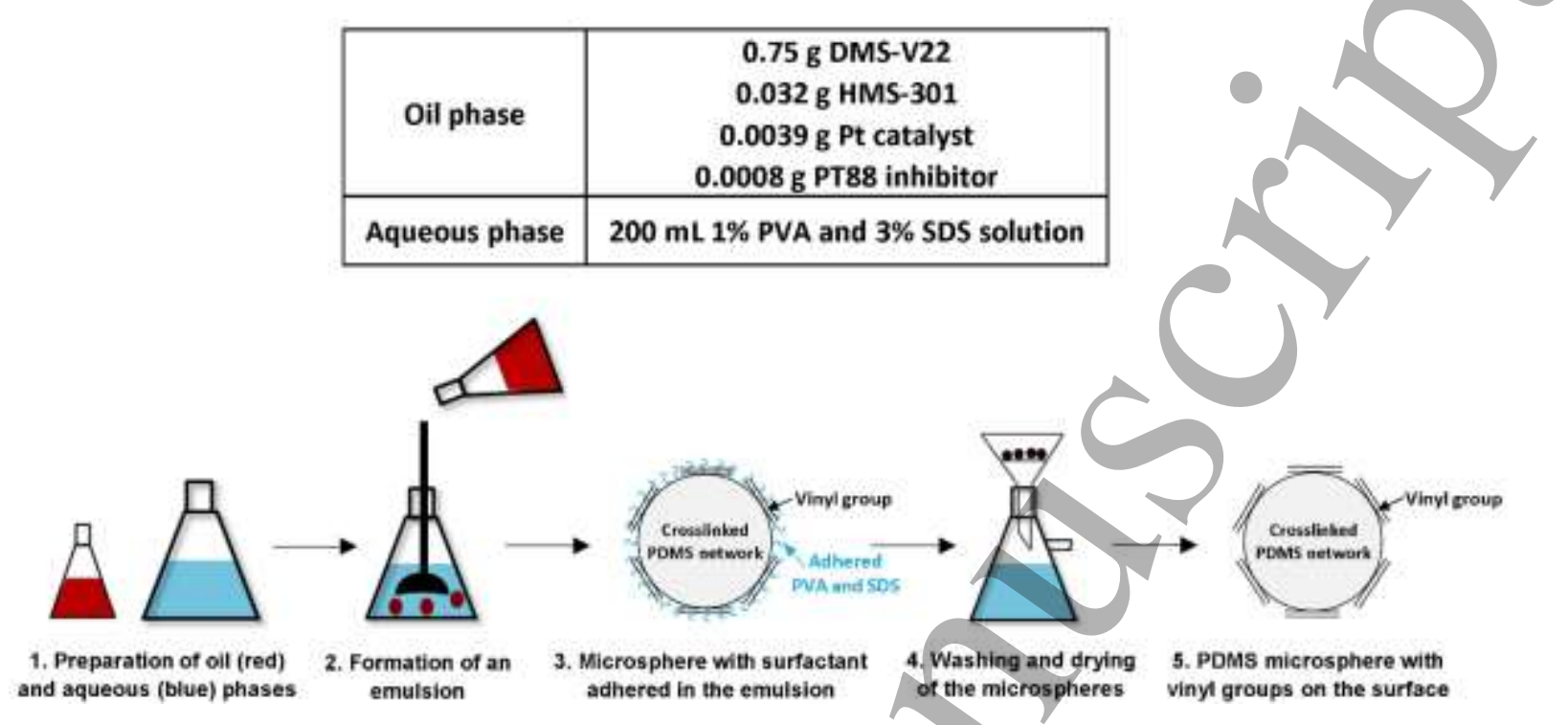

Figure 3. Schematic presentation of the emulsion method. The table specifies particular conditions used during microsphere preparation.

\subsection{Preparation of cross-linked plugging samples}

The magnetic microcapsules and the vinyl-functional microspheres were physically mixed using a SpeedMixer with various mass ratios (1:10, 1:20, and 1:30). The mixture samples were heat-treated by AMF with different frequencies, which was performed using a MagneTherm instrument (Nanotherics). The samples were placed in the centre of a 17-loop induction coil. A non-contact IR thermometer (Fluke VT04 Visual) was used to detect temperature changes in the samples during the AMF treatment, which were performed in three cycles of 20 minutes, to avoid overheating the induction coil. Due to release of the cross-linker at temperatures higher than the $T_{g}$ of the PMMA shell in the magnetic microcapsules, a cross-linking reaction would take place with the vinyl-functional microspheres. 


\subsection{Analytical methods}

Optical microscopy images were taken using a portable Dino-Lite Edge digital microscope AM4115ZT (Dunwell Tech, Inc, USA). Scanning electron microscopy (SEM) images were recorded on an FEI Quanta 200 SEM (Thermo Fisher Scientific, USA) on samples coated with 2 nm-thick gold, using a Cressington 208HR sputter coater (Cressington Scientific Instruments, UK). Cryo-SEM was operated to show the cross-section of a PMMA microcapsule. The microcapsule sample was plunge frozen in liquid nitrogen on the cryo-stage of SEM and fractured in order to produce a fresh cross-section. The frozen fractured microcapsule was kept at $\sim-140{ }^{\circ} \mathrm{C}$ below the glass transition temperature of the core liquid HMS-301 $\left(\sim-120^{\circ} \mathrm{C}\right)$ and imaged with an electron beam accelerated to the equilibrium voltage observed by SEM.

Thermogravimetric analysis (TGA) was performed using a TGA Discovery instrument (TA Instruments, USA), ranging from $20{ }^{\circ} \mathrm{C}$ to $800{ }^{\circ} \mathrm{C}$ with a heating rate of $10{ }^{\circ} \mathrm{C} / \mathrm{min}$ in an $\mathrm{N}_{2}$ atmosphere. The $\mathrm{T}_{\mathrm{g}}$ of the shell polymer PMMA was measured by employing differential scanning calorimetry (DSC) (Discovery, TA Instruments, USA) in the range of $0{ }^{\circ} \mathrm{C}$ to $150{ }^{\circ} \mathrm{C}$ at heating/cooling rates of $10{ }^{\circ} \mathrm{C} / \mathrm{min}$ in an $\mathrm{N}_{2}$ atmosphere. $\mathrm{T}_{\mathrm{g}}$ was calculated by a second heating scan, as the temperature of the halfway point of the jump in heat capacity when the material changed from a glassy to a rubbery state. ${ }^{1} \mathrm{H}$ NMR characterisation was performed on a Bruker $250 \mathrm{MHz}$ spectrometer (Bruker, Germany), using $\mathrm{CDCl}_{3}$ as a solvent. All spectra were recorded across 32 scans. Rheological measurements of the cross-linking behaviour were carried out in an inert nitrogen atmosphere, using a strain-controlled shear rheometer (ARESG2, TA instruments, USA) set to a controlled strain mode with $2 \%$ strain, which was ensured to be within the linear regime of the material based on an initial strain sweep test. Timeresolved dynamic-mechanical mixture experiments were performed at a constant frequency of $1 \mathrm{~Hz}$ by applying a parallel plate geometry of $25 \mathrm{~mm}$ in diameter and a gap of $1 \mathrm{~mm}$ at $50{ }^{\circ} \mathrm{C}$ and $90^{\circ} \mathrm{C}$. The linear visco-elastic (LVE) data for the cross-linked samples were measured 
with parallel-plate geometry of $25 \mathrm{~mm}$ at a diameter of $23{ }^{\circ} \mathrm{C}$. The LVE diagrams were obtained from frequency sweeps ranging from $100 \mathrm{~Hz}$ to $0.01 \mathrm{~Hz}$. A non-contact VT04 Visual IR thermometer (Fluke, USA) was used to detect temperature changes in the samples during the AMF treatment by a MagneTherm instrument (Nanotherics, UK).

\section{Results and discussion}

\subsection{Activation of the magnetite nanoparticles in AMF}

Figures $4 \mathbf{a}$ and $\mathbf{b}$ present SEM images of the magnetite nanoparticles $\mathrm{Fe}_{3} \mathrm{O}_{4}$ without and with PDMS surface modification, respectively. The particles were spherical and their diameters were between 20 and $60 \mathrm{~nm}$.

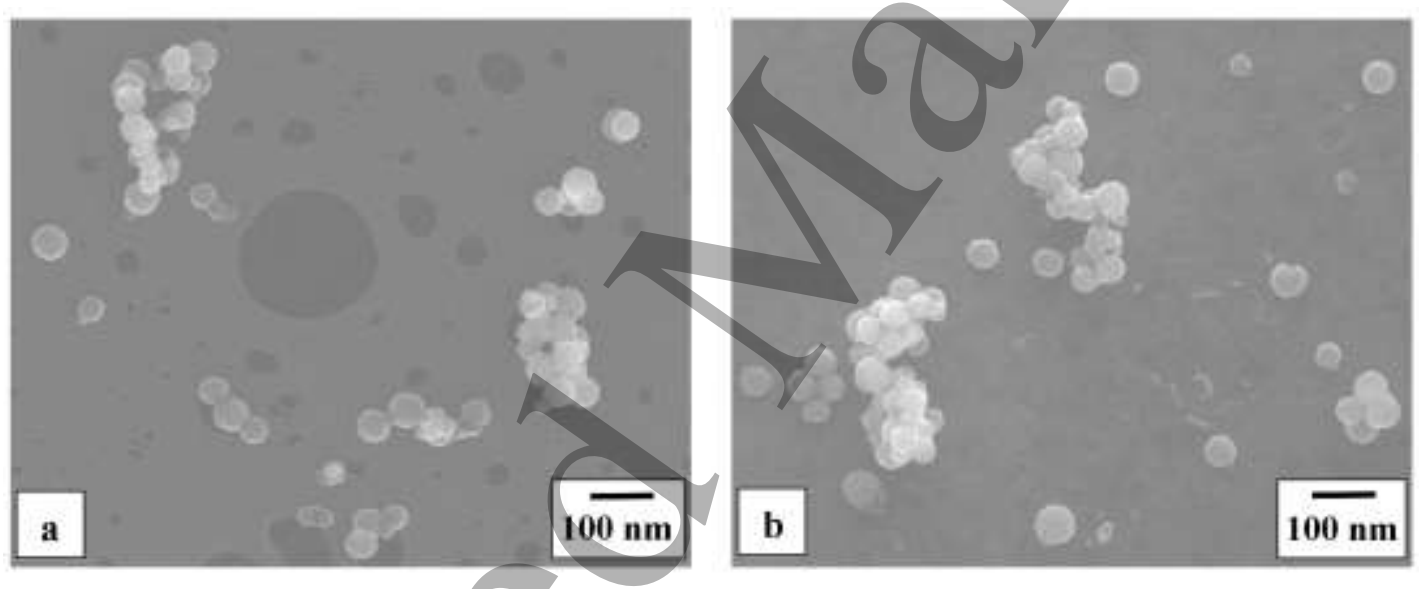

Figure 4. SEM pictures of magnetite nanoparticles. a) $\mathrm{Fe}_{3} \mathrm{O}_{4}$. b) $\mathrm{Fe}_{3} \mathrm{O}_{4}-\mathrm{PDMS}$.

When the polymer mixtures incorporating MNPs were exposed to the AMF, the MNPs dissipated the energy to the surrounding matrix, due to friction between the oscillating magnetic particles and the stationary matrix [16]. Consequently, AMF generates heat rapidly and locally, compared to supplying heat directly to thermally insulating materials, e.g. silicone [14]. In order to determine which type of MNP can generate sufficient heat to soften the PMMA shell, aqueous mixtures with 5\% MNP mass content were prepared and exposed to AMF for 
20 minutes at various frequencies, since the thermal response of the magnetic composite through exposure to an AMF depends on the frequency of the magnetic field [26]. A frequencyresponse profile of magnetic particles dispersed in the aqueous mixtures is presented in Figure

5. The available nominal frequencies of MagneTherm instrument are noted on the $\mathrm{x}$-axis. The highest temperatures were obtained at a frequency of $110 \mathrm{kHz}$ for both MNPs.

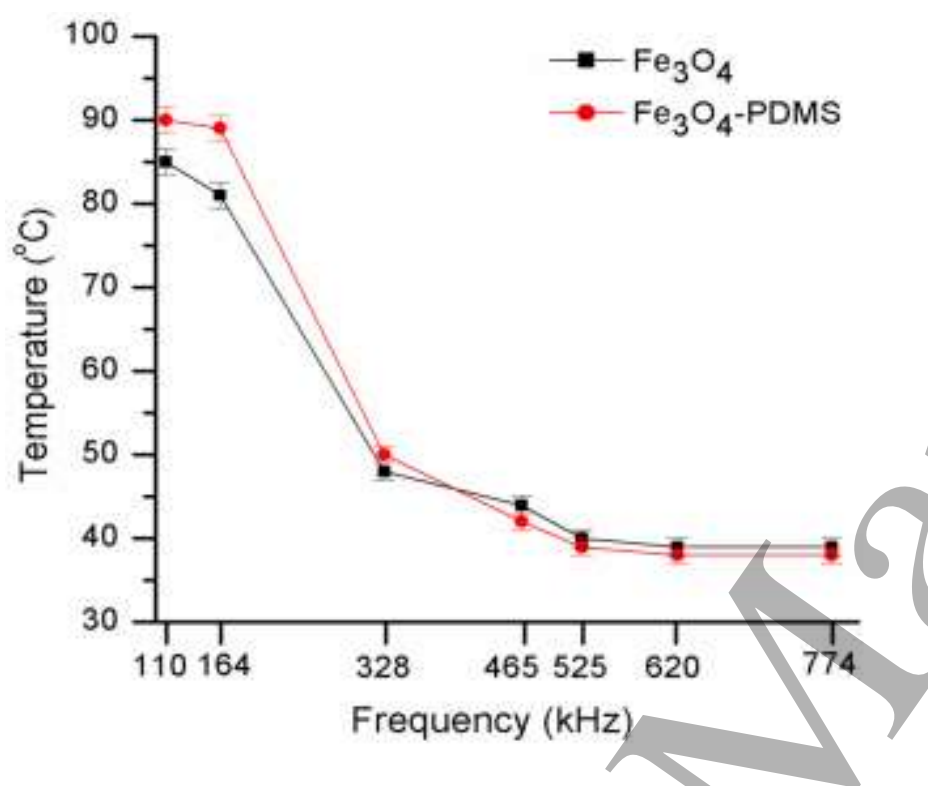

Figure 5. AMF frequency-dependent temperature elevation of the aqueous mixtures with a 5\%-mass content of MNPs. The two different MNPs was examined by the exposure to the AMF for 20 minutes at various frequencies. The error bars were calculated from the triplicate measurements.

In Figure 5, the mixture containing 5wt.\% of $\mathrm{Fe}_{3} \mathrm{O}_{4}-\mathrm{PDMS}$ nanoparticles reaches the highest temperature of all mixtures at $90{ }^{\circ} \mathrm{C}$ at $110 \mathrm{kHz}$, showing the possibility of melting the PMMA shell with $\mathrm{T}_{\mathrm{g}}$ equal to $88^{\circ} \mathrm{C}$ (Figure S1). According to the quantitative analysis of magnetic microcapsules by TGA and NMR (ESI), MNPs constituted more than $30 \%$ of the core mass. Therefore, during exposure to the AMF, the encapsulated nanoparticles were able to generate sufficient heat to increase the temperature higher than $90{ }^{\circ} \mathrm{C}$ and thereby soften the 
PMMA shell, thus allowing for the efficient release of the liquid cross-linker. However, it was shown that the mixture with $\mathrm{Fe}_{3} \mathrm{O}_{4}$ nanoparticles reached $85^{\circ} \mathrm{C}$ at $110 \mathrm{kHz}$, thereby indicating that the PMMA shell might not be softened enough by the application of the AMF because the generated temperature was lower than the $\mathrm{T}_{\mathrm{g}}$ of PMMA $\left(88^{\circ} \mathrm{C}\right)$.

\subsection{Microscopical characterisation of the magnetic microcapsules}

As the $\mathrm{MNP} \mathrm{Fe}_{3} \mathrm{O}_{4}$ exhibited sufficient heat generation under an AMF with a frequency of 110 $\mathrm{kHz}$ to make the PMMA soft, as well its well-dispersion in the hydrophobic cross-linker due to the PDMS surface modification, it was selected to be encapsulated together with a liquid cross-linker via the phase separation technique, following the procedure given in the experimental chapter.

Figures 6a and $\mathbf{b}$ present the secondary electron (SE) images of the microcapsules with $\mathrm{Fe}_{3} \mathrm{O}_{4}$-PDMS nanoparticles. All the microcapsules were spherical and their diameter fell between 20 and $150 \mu \mathrm{m}$ (Figure 6a). It is obvious that no nanoparticles or pores were present on the shell's surface (Figure 6b). The continuous surface shows that the PMMA shell encapsulated successfully the cross-linker which is located at the core. Figure $\mathbf{6 c}$ presents a microcapsule imaged in bright-field scanning transmission electron microscopy (STEM) mode of SEM. The SE imaging is sensitive to the surface topography, while the STEM imaging is in projection along an electron beam, which allows the internal structure of a specimen to be imaged at relatively high resolution. The comparison of the two images suggests that dark contrast in the STEM corresponds to MNPs that are located inside the microcapsule. It is noted that these visible MNPs would be the aggregation of nanometer-sized MNPs as shown in

Figure $4 \mathbf{b}$. Figure $6 \mathbf{d}$ shows a cross-section of a microcapsule, which was acquired at a temperature $\left(\sim-140^{\circ} \mathrm{C}\right)$ below the glass transition temperature of the crosslinker, HMS-301. The image clearly shows a core/shell structure, which is composed of the crosslinker (core) 
and $~ 5-\mu$ m-thick PMMA (shell). The interface between the crosslinker and the PMMA is rather rough, while the outer surface of the PMMA shell is smooth, which can also be observed in the SE image shown in Figure 6b. The MNPs are located only in the crosslinker with relatively well dispersion, indicating that a temperature rise induced by AFM may occur uniformly in the crosslinker. Although various sized pores with up to $2 \mu \mathrm{m}$ are present in the PMMA shell, the pores have smaller sizes than the shell thickness and are not exposed to the surface. Therefore, the crosslinker inside the microcapsules would not be released to the outside as it is. When AMF is applied to the MNPs dispersed in the microcapsules, the MNPs would produce sufficient heat to soften the PMMA shell and release the cross-linker from the microcapsules.

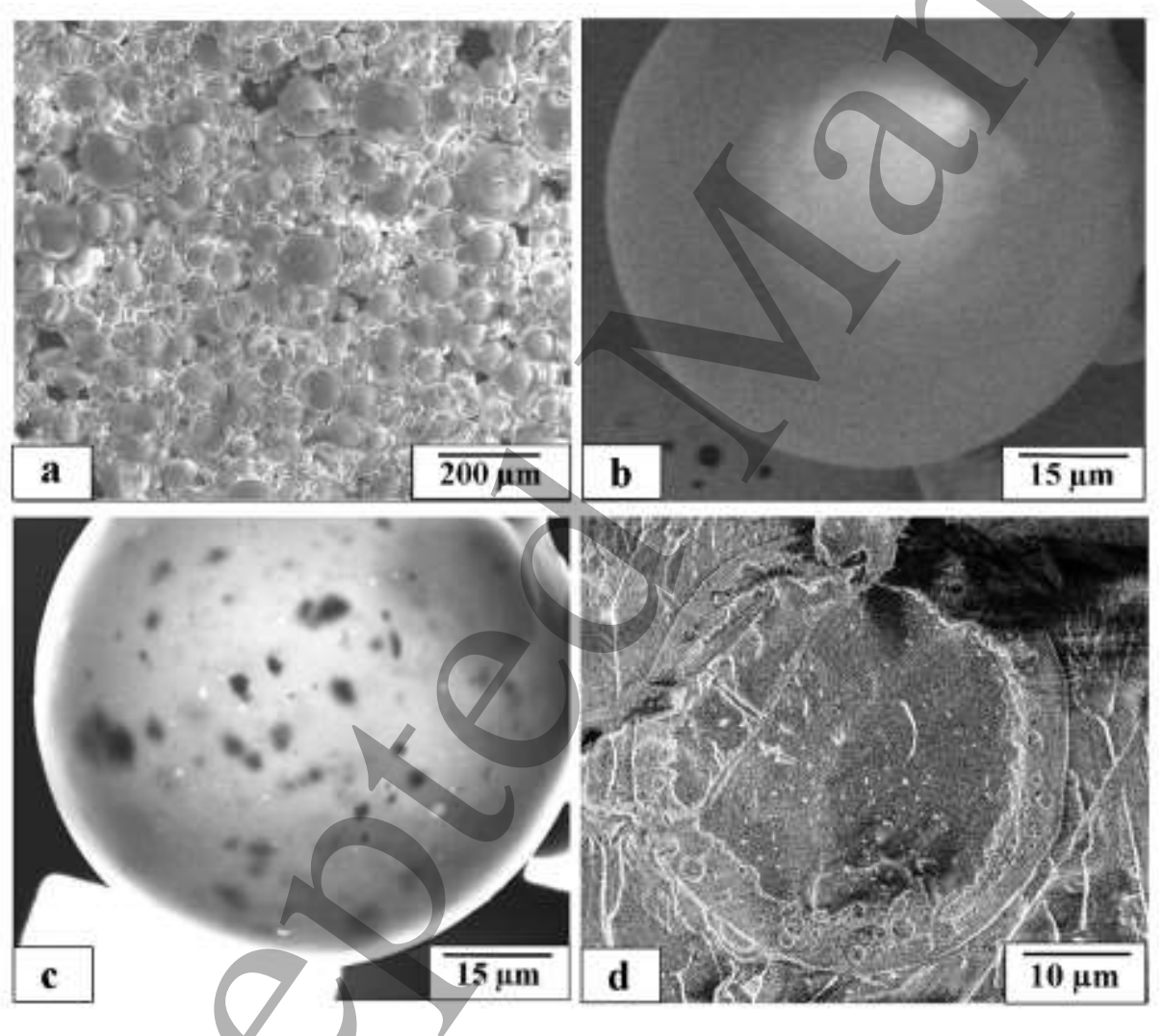

Figure 6. $\mathrm{SEM}$ photographs of microcapsules containing the $\mathrm{Fe}_{3} \mathrm{O}_{4}-\mathrm{PDMS}$ nanoparticles. a) Low magnification SE image of a microcapsule aggregation. b) and c) SE and bright-field STEM images of a single microcapsule. The images $\mathbf{b}$ ) and $\mathbf{c}$ ) were acquired from the same 
microcapsule. Dotted-like bright contrast in c) corresponds to pores in the shell. d) SE image of a cross-section of a microcapsule obtained around $-140^{\circ} \mathrm{C}$ by cryo-SEM.

\subsection{Cross-linked plugging samples containing magnetic microcapsules and PDMS} microspheres

Magnetic microcapsule reactivity was investigated by means of rheology. The microcapsules were mixed with the PDMS premix with a mass ratio 1:10, which was shown previously to be the suitable ratio to obtain a strong low-loss tangent $(\operatorname{Tan} \delta<0.1 @ 1 \mathrm{~Hz})$ network [27]. The PDMS premix consisted of the vinyl-terminated poly(dimethylsiloxane) DMS-V31 with 50 ppm of a platinum catalyst. Two identical mixtures were then investigated at different temperatures, and the storage modulus (G') and loss modulus $\left(G^{\prime \prime}\right)$ are presented in Figure 7.

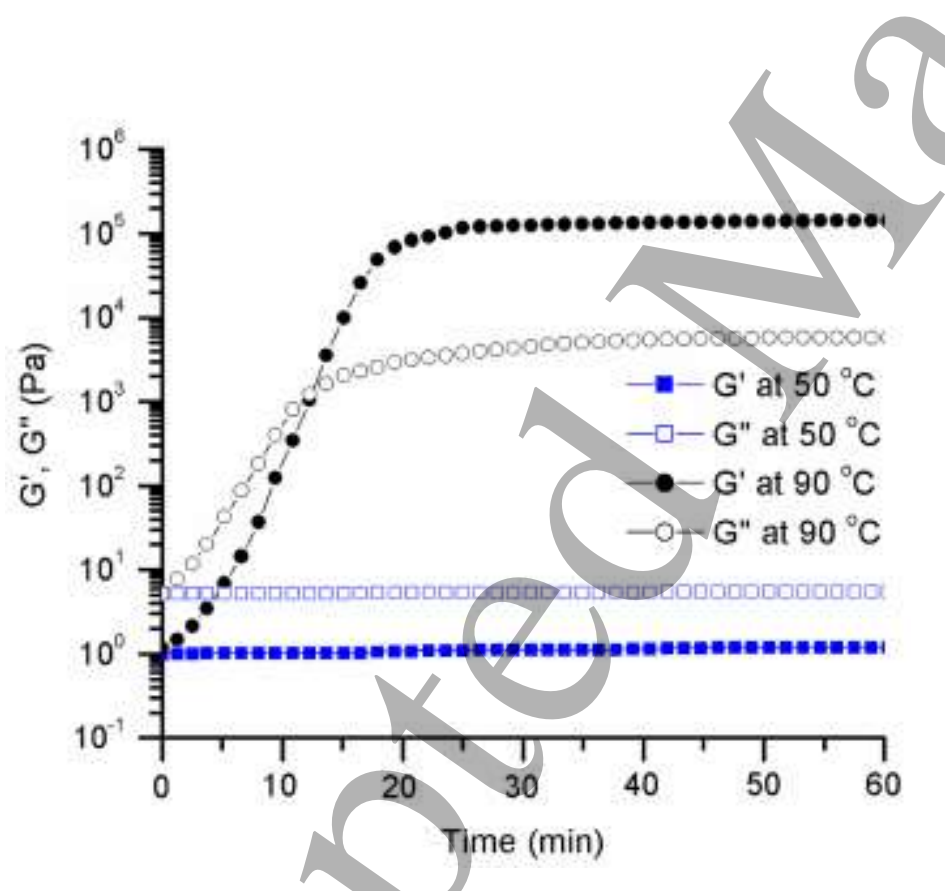

Figure 7. Development of storage and loss moduli ( $G^{\prime}$ and $\left.G^{\prime \prime}\right)$ of the mixtures containing a PDMS premix (DMS-V31 with platinum catalyst) and magnetic microcapsules. The measurements were performed at $1 \mathrm{~Hz}$ at $50{ }^{\circ} \mathrm{C}$ and $90{ }^{\circ} \mathrm{C}$ controlled by rheometer, respectively, for 1 hour. 
The performed tests showed that the magnetic microcapsules were impermeable at $50{ }^{\circ} \mathrm{C}$ heated by rheometer oven, as both moduli remained constant over time during the one-hour experiment. G' (loss modulus) was higher than G' (storage modulus) during the entire measurement phase, implying that the cross-linker was not released and therefore the crosslinking reaction was not initiated. At $90{ }^{\circ} \mathrm{C}$, as expected, the PMMA became soft and pliable, and the microcapsules disintegrated, thereby releasing the cross-linker. This led to the formation of the three-dimensional network of vinyl-terminated PDMS reacted with hydridefunctional cross-linker and a subsequent increase in the storage modulus, which reached a plateau after approximately 20 minutes, with values significantly higher than the loss modulus, thus confirming the formation of the strong PDMS network. Furthermore, gelation was achieved at around 13 minutes.

After identifying the reactivity of the magnetic microcapsules at $90{ }^{\circ} \mathrm{C}$, the cross-linked plugging samples made from the vinyl-functional PDMS microspheres and the magnetic microcapsules were examined. As seen in Figure 7, at $90^{\circ} \mathrm{C}$ the dynamic moduli G' and G" reached steady state after 1 hour, so AMF experiments were performed in three cycles of 20 minutes to avoid overheating the induction coil. Figure $\mathbf{8}$ shows a schematic presentation and microscopic images of the magnetic microcapsules and the PDMS microspheres (mixed mass ratio 1:10), before and after the cross-linking reaction. Before the reaction, the PDMS microspheres were not connected to each other. The cross-linker was released after exposing microcapsules with $\mathrm{Fe}_{3} \mathrm{O}_{4}-\mathrm{PDMS}$ nanoparticles to $\mathrm{AMF}$ at $110 \mathrm{kHz}$ for an hour. Non-reactive silicone oil with a platinum catalyst was used as a reaction matrix to enable a hydrosilylation reaction between the PDMS microspheres and the released cross-linker. After the reaction, the PDMS microspheres were connected through inter-spherical covalent bonds [28]. 


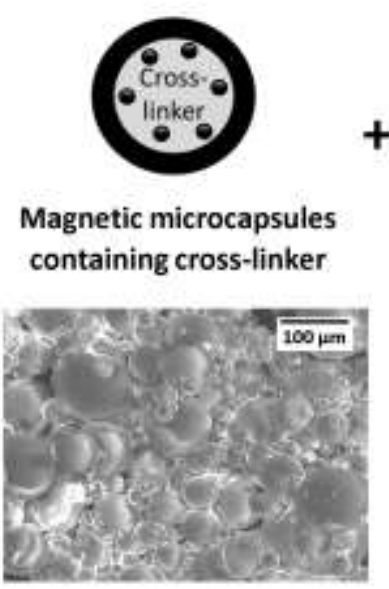

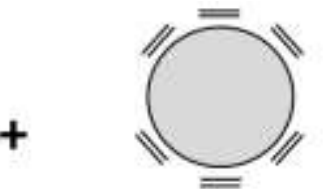

PDMS microspheres with vinyl groups on the surface

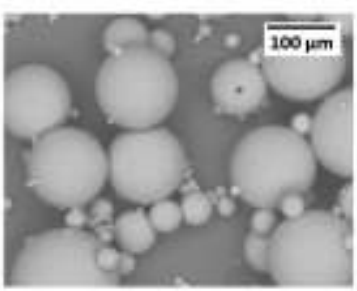

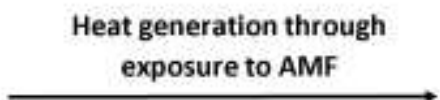
and microspheres before AMF treatment

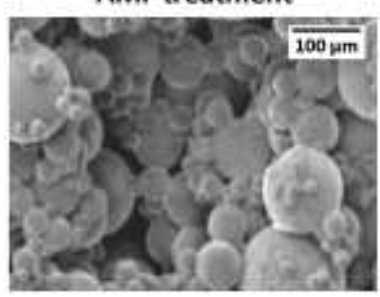

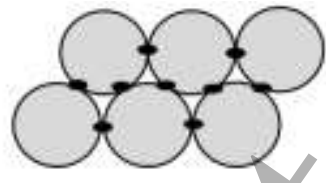

Connected PDMS microspheres due to release of the cross-linker

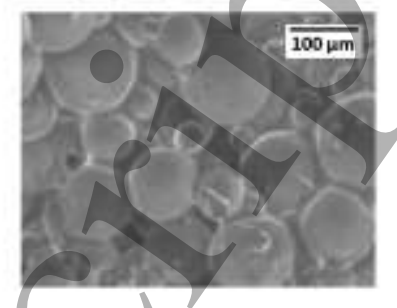

Figure 8. Schematic presentation and SEM images of the magnetic microcapsules and the PDMS microspheres, before and after the cross-linking reaction.

Figure 9a shows optical microscopy images of the cross-linked plugging samples with different microcapsule-to-PDMS microsphere mass ratios. Since the microcapsules contained MNPs, distinguishing them from the microspheres is possible between portions of bright microspheres and dark MNPs. It is evident that the microcapsules were dispersed well within the sample through the speed mixing treatment, without the occurrence of obvious agglomerations, thereby resulting in the homogeneous distribution of a released cross-linker. When the cross-linker is spread uniformly, the cross-linking density of PDMS microspheres is similar throughout the whole volume and therefore leads to the formation of a uniform network.

a)

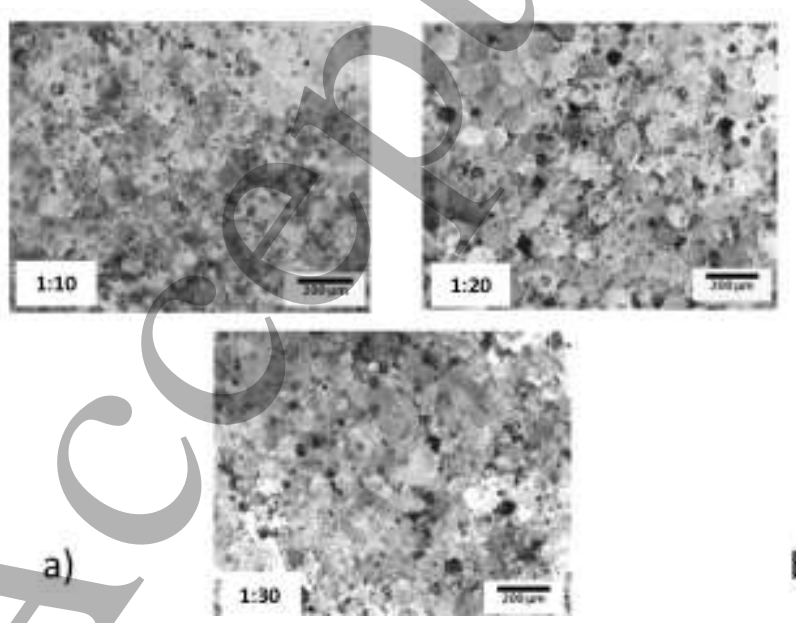

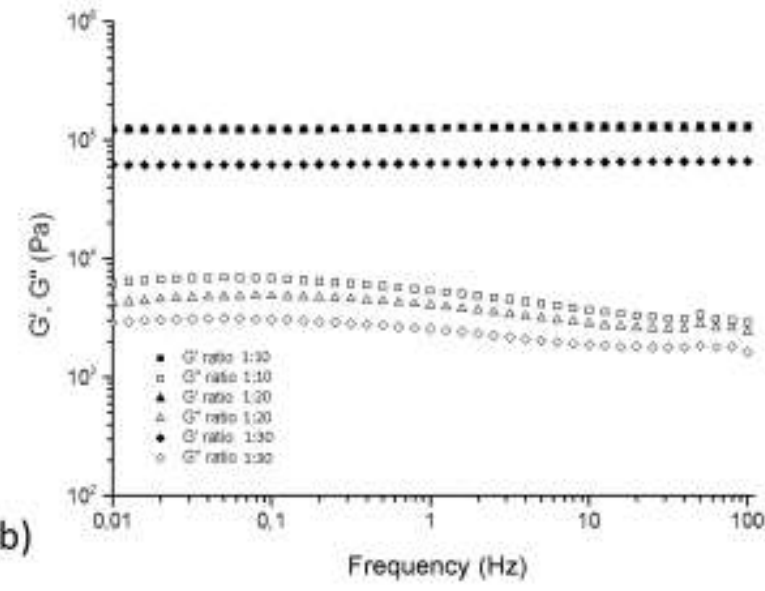


Figure 9. Morphology and viscoelasticity of the cross-linked plugging samples containing magnetic microcapsules and vinyl-functional PDMS microspheres. a) Optical microscopy images. b) The storage (G') and the loss (G', ) moduli as a function of applied frequency. The mass ratios of the microcapsule to the microsphere are stated on the images and graph.

From frequency sweep tests, the storage $\left(\mathrm{G}^{\prime}\right)$ and the loss moduli $\left(\mathrm{G}^{\prime \prime}\right)$ of the cross-linked plugging samples with various magnetic microcapsule-to-PDMS microspheres ratios were measured, as seen in Figure 9b. In three different storage moduli curves, the values of G' were independent of the frequency, meaning that the released liquid cross-linker took part in a hydrosilylation reaction and led to covalent bonding between the PDMS microspheres. Moreover, despite the fact that the cross-linked sample was formed from individual microspheres, it can be considered a uniform and well-organised material. Furthermore, the values of G' for three samples were very similar, the samples with the ratios 1:10 and 1:20 had an almost identical storage modulus, whereas the sample with the 1:30 ratio had only a slightly lower G'. This proved that regardless of the ratio between the compounds, the cross-linked samples showed similar mechanical properties, thus demonstrating that deviations in ratios between the compounds (within the tested range) will not have a negative impact on the final properties of the plug inside the fracture, and thus the sensitivity of the system on the mixing ratio is low.

\section{Conclusions}

A cross-linked plugging material consisting of magnetically activated microcapsules and vinylfunctional PDMS microspheres was prepared successfully. Encapsulating the cross-linker provided control over the cross-linking reaction between the vinyl-functional microspheres, whereas incorporating magnetite nanoparticles (MNPs) into the microcapsules' structure 
introduced the possibility of remote activation by applying the alternating magnetic field (AMF). While applying AMF, the MNPs generated heat, and a 5wt.\% aqueous mixture of the $\mathrm{Fe}_{3} \mathrm{O}_{4}$ nanoparticles with a PDMS surface modification at $110 \mathrm{kHz}$ reached $90{ }^{\circ} \mathrm{C}$ higher than the $\mathrm{T}_{\mathrm{g}}\left(88^{\circ} \mathrm{C}\right)$ of the PMMA shell. The obtained magnetic microcapsules, prepared via the phase separation technique, contained high amounts of the MNPs (>15wt.\%), which were located inside the microcapsules. The structure of the PMMA shell was not influenced by the presence of the MNPs and remained non-porous; hence, the magnetic microcapsules were impermeable at temperatures lower than the $\mathrm{T}_{\mathrm{g}}$ of the shell, and the cross-linker was separated fully from the environment until microcapsule activation. This notion was proved by mixing the microcapsules with vinyl-terminated PDMS, and the cross-linking reaction was observed only at temperatures higher than the $\mathrm{T}_{\mathrm{g}}$ of the shell. Moreover, vinyl-functional PDMS microspheres mixed with the magnetic microcapsules created a strong network after the crosslinking reaction. The microcapsules were distributed uniformly within the whole volume of the network, thus enabling good bonding between the microspheres. It was presented that deviations in the mass ratio between the magnetic microcapsules and the PDMS microspheres did not influence the elastic properties of the cross-linked sample, which is of great importance regarding application in oil recovery treatments, where the mass ratio cannot be controlled precisely.

\section{Acknowledgements}

The authors wish to express our thanks to Ramona Valentina Mateiu (Hempel Foundation Coatings Science and Technology Center, DTU) for invaluable discussion on the SEM investigation. The authors gratefully acknowledge Mærsk Oil \& Gas Research, Qatar for the financial sulpport and the A.P. Møller and Chastine Mc-Kinney Møller Foundation for the 
contribution towards the establishment of the Center for Electron Nanoscopy in the Technical University of Denmark.

\section{References}

[1] Hadia N, Chaudhari L, Mitra S K, Viniamur M and Singh R 2007 J. Pet. Sci. \& Eng. 56 303

[2] Kok M V 2011 Energy Sources, Part A Recover. Util. Environ. Eff. 33377

[3] Marescalco P A C 2008 Int. J. Numer. Methods Fluids 61768

[4] Bai B, Zhou J and Yin M 2015 Pet. Explor. Dev. 42525

[5] Oglesby K D, D’Souza D, Roller C, Longsdon R, Burns L D and Felber B J 2016 SPE Improved Oil Recovery Conference held in Tulsa, USA 1-25

[6] Hassan S F, Han M, Zhou X, Krinis D, Zahrani B and Aramco S 2013 SPE Annual Technical Symposium and Exhibition held in Khobar, Saudi Arabia 1-11

[7] Simjoo M, Koohi A D, Vafaie-Sefti M and Zitha P L J 2009 SPE European Formation Damage Conference held in Scheveningen, The Netherlands 1-8

[8] Al-Muntasheri G A, Sierra L, Garzon F O, Lynn J D and Izquierdo G 2010 SPE Improved Oil Recovery Symposium held in Tulsa, USA 1-24

[9] Ryles R and Cicchiello J 1986 SPE/DOE Fifth Symposiumon Enhaced Oil Recovery of the Society of Petroleum Engineers of the Department of Energy held in Tulsa, USA 301-305 [10] Madsen F B, Daugaard A E, Hvilsted S and Skov A L 2016 Macromol. Rapid Commun. 37378

[11] Larsen A L, Hansen K, Sommer-Larsen P, Hassager O, Bach A, Ndoni S and Jørgensen M 2003 Macromolecules 3610063

[12] Vaishnava P P, Tackett R, Dixit A, Sudakar C, Naik R and Lawes G 2007 J. Appl. Phys. 10263914 
[13] Tomitaka A, Ueda K, Yamada T and Takemura Y 2012 J. Magn. Magn. Mater. 3243437

[14] Regmi R, Naik A, Thakur J S, Vaishnava P P and Lawes G 2014 J. Appl. Phys. 115 17B301

[15] Suto M, Hirota Y, Mamiya H, Fujita A, Kasuya R, Tohji K and Jeyadevan B 2009 J. Magn. Magn. Mater. 3211493

[16] Ogliani E, Yu L, Javakhishvili I and Skov A L 2018 RSC Adv. 88285

[17] Li J, Gu J, Li H, Liang Y, Hao Y, Sun X and Wang L 2010 Micropor. Mesopor. Mat. 128 144

[18] Pan S, Li J, Wan G, Liu C, Fan W and Wang L 2016 J. Hazard. Mater. 3091

[19] Gleich B and Weizenecker J 2005 Nature 4351214

[20] Krishnan K M 2010 IEEE Trans. Magn. 462523

[21] Chung S H, Hoffmann A and Bader S D 2004 Appl. Phys. Lett. 852971

[22] Liu J, Sun Z, Deng Y, Zou Y, Li C, Guo X, Xiog L, Gao Y, Li F and Zhao D 2009 Angew. Chem. Int. Ed. 48 5875-5879

[23] González L, Kostrzewska M, Ma B, Li L, Hansen J H, Hvilsted S and Skov A L 2014 Macromol. Mater. Eng. 2991259

[24] Ma B, Hansen J H, Hvilsted S and Skov A L 2014 RSC Adv. 447505

[25] González L, Ma B, Li L, Hansen J H, Hvilsted S and Skov A L 2014 Macromol. Mater. Eng. 299729

[26] Hohlbein N, Shaaban A and Schmidt A M 2015 Polymer 69 301-309

[27] Kostrzewska M, Ma B, Javakhishvili I, Hansen J H, Hvilsted S and Skov A L 2015 Polym. Adv. Technol. 261059

[28] Brook M A Silicon in Organic, Organometallic, and Polymer Chemistry 2000 John Wiley \& Sons, New York, United States 